\title{
Situational Interest and Learning in a Science Center Mathematics Exhibition
}

\author{
Mari-Pauliina Vainikainen ${ }^{\mathrm{a}}{ }^{1}$, Hannu Salmi ${ }^{\mathrm{a}}$, Helena Thuneberg ${ }^{\mathrm{b}}$ \\ ${ }^{a}$ Centre for Educational Assessment, University of Helsinki, Finland \\ ${ }^{\mathrm{b}}$ Department of Teacher Education, University of Helsinki, Finland
}

\begin{abstract}
Educators have been increasingly interested in teaching mathematics in informal settings. However, there is little research on the actual learning outcomes of out-of-school mathematics instruction or the role of interest in explaining the outcomes. In this study, 793 12-year-old pupils were taken into a science center mathematics exhibition in Latvia and Sweden, measuring their prior knowledge of the contents of the exhibition, general cognitive competences and individual interest in school mathematics before the visit, and their situational interest and learning outcomes after the exhibition. In the exhibition, the pupils learned how to form concrete, hands-on geometrical models and physical structures based on abstract instructions. The results showed that both boys and girls learned during the exhibition, but contrary to the expectations, there were no gender differences in either learning outcomes or interest. Individual interest predicted situational interest, which was a positive predictor of learning outcomes. It was concluded that more attention should be paid to how situational interest and motivation, which are typical in out-of-school learning contexts, can be utilized in enhancing learning outcomes of children of all age groups.
\end{abstract}

Keywords: Science center; Learning outcomes; Out-of-school mathematics education; Situational interest; Individual interest

Educators have been increasingly interested in teaching mathematics in informal settings and using cross-disciplinary methods due to the recent changes in the society (Fenyvesi, Koskimaa, \& Lavicza, 2015). It is assumed that utilizing out-of-school learning environments would be useful particularly for pupils who face difficulties in traditional learning situations in the classroom. This assumption has over the recent decades been supported by a large body of evidence from the fields of interdisciplinary and inquiry-based mathematics (Artigue \& Blomhøj, 2013). According to Resnick (1987), this is because the practice-oriented tool manipulation approach and contextualized reasoning facilitate the learning of contents that are typically taught using mentation and symbol manipulation. Also, out-of-school environments may produce effects on pupils' motivation or interest and thereby on their learning (Braund \& Reiss, 2004; Csikszentmihalyi \& Hermanson, 1995; Frantz-Pittner, Grabner, \& Bachmann, 2011; Salmi 2003; Thuneberg, Salmi, \& Vainikainen, 2014). However, there is relatively little research on the actual learning outcomes of teaching mathematics outside the school walls and how interest is related to learning in out-of-school settings. To study this interesting phenomenon, 793 12-year-old pupils were taken into a science center mathematics exhibition in Latvia and Sweden, measuring their prior knowledge of the contents of the exhibition, general cognitive competences and individual interest in school mathematics before the visit, and their situational interest and learning outcomes after the exhibition. In the present article we take a look at how individual interest in school mathematics and situational

${ }^{1}$ Corresponding author. Centre for Educational Assessment, P.O. Box 9, 00014 University of Helsinki, Finland.

E-mail: mari-pauliina.vainikainen@helsinki.fi

Vainikainen, M-P, Salmi, H., \&Thuneberg, H. (2015). Situational interest and learning in a science center mathematics exhibition. Journal of Research in STEM Education. 1(1), 15-29 
interest in the science center mathematics exhibition influenced the learning outcomes of the pupils who visited the exhibition and discuss in detail gender differences in interest and learning in an out-of-school learning situation.

\section{Theoretical Framework and Review of Relevant Literature}

\section{Interest and learning}

Interest is an important cognitive and affective motivational factor guiding attention and facilitating learning in different contexts (Renninger \& Hidi, 2011). Interest is at least indirectly related to learning and achievement outcomes even when controlling for prior ability and it typically accounts for approximately $10 \%$ of the variance of performance (Ainley, Hidi \& Berndorff, 2002a; Schiefele, Krapp, \& Winteler, 1992; Van Yperen, 2003). Ainley and colleagues (2002a) showed that the mechanism of the influence is relatively complex, with interest being related to affective response, the affective response to persistence, and the persistence to learning outcomes. Interest may be a particularly important factor when trying to understand mathematic performance and possible gender differences in it as students tend to sustain an aversion towards mathematics (Ma \& Kishor, 1997; Gomez-Chacon, 2000) while remaining largely ignorant of how deeply mathematics is embedded in the world around them (Hannula, 2012). The connection between attitudes and interest with mathematic performance has been showed by earlier meta-analyses (Ma \& Kisher, 1997) as well as by recent large-scale assessment studies (OECD, 2013). It has also been shown that regardless of the minimal or even opposite gender differences in school grades and performance, boys report more interest and enjoyment in mathematics than girls (Frenzel, Goetz, Pekrun, \& Watt, 2010; Frenzel, Pekrun, \& Goetz, 2007).

The interest development of school-age children can be supported by the tasks and the organization of the learning environment (Renninger \& Hidi, 2011). The dilemma faced by the science exhibitions is whether they are capable of managing to orient and enhance the momentary, strong situational interest and motivation into a long-lasting intrinsic motivation. This is also one of the biggest challenges for open learning environments, such as science centers (Salmi 1993, 2003; Salmi, Sotiriou and Bogner 2009). As Hidi and Ainley (2009) put it: "Whereas the potential for interest resides in the person, the content and the environment may determine the direction of interest and contribute to its development". Therefore, studying the effects of interest in learning outcomes in the context of the present study is important.

There are several theories about the different forms of interest and its development (see Renninger \& Hidi, 2011, for a review). Interest can be conceptualized as a part of intrinsic motivation, which refers to engaging in activities for the activity itself (Urdan \& Turner, 2005). On the other hand, it has been claimed that interest as such is never entirely either intrinsically or extrinsically motivated but it varies depending on the phase of interest development and the situation (Hidi \& Harackiewicz, 2000). Many theories regarding interest development recognize the distinction between individual and situational interest. Individual interest can be defined as a psychological state characterized by focused attention, increased cognitive and affective functioning, and persistent effort, which can be seen as an individual's predisposition to attend to certain stimuli, events, and objects - including school subjects (Ainley et al., 2002a). Situational interest, on the other hand, depends on aspects of the environment including the ways the learning situation is organized (Ainley et al., 2002a). Situational interest is based on an affective reaction, which can include a broad range of emotions, and there is a great variation in how this reaction is maintained (Ainley et al., 2002a). In addition, Ainley and colleagues write about triggered topic interest, which seems to have both individual and situational aspects. In the present study, interest is measured in two contexts: pupils' general interest in learning mathematics in school is used as an indicator of their individual interest, whereas situational interest is measured as their experience of learning mathematics during the science center visit.

According to Hidi and Renninger (2006), interest develops in four stages, but measures for distinguishing them empirically are still under development (Renninger \& Hidi, 2011). The first stage is triggered situational interest, which can evolve into maintained situational interest. Emerging individual interest can 
then develop out of the second stage, and finally it can lead to a well-developed individual interest (Hidi \& Renninger, 2006). In a novel learning situation, pupils with a more developed individual interest have been shown to have better possibilities to experience related situational interest (Renninger \& Hidi, 2011). On the other hand, situational sources of interest are particularly important when dealing with pupils who do not have prior individual interest in school activities (Ainley et al., 2002a) even if pupils with only a triggered interest are not always able to purposefully identify goals for learning or decide to self-regulate in order to learn (Renninger, Sansone, \& Smith, 2004). There is evidence from young adults that students with less interest for mathematics responded positively to task novelty, but novelty had a negative influence for those with more interest for mathematics (Durik \& Harackiewicz, 2007). In general, school-age pupils' individual interest for school subjects has been shown to decrease when they get older, but it can also develop positively if assignments and the learning environment support it (Renninger \& Hidi, 2011).

There are some important gender differences in interest, which need to be taken into account in the present study. In their study on gender differences in interest, Ainley, Hillman and Hidi (2002b) review literature which suggests that boys can be more vulnerable to the effects of task characteristics, and interesting tasks - or in the case of the present study an interesting learning environment - can enhance their performance significantly. Accordingly, in the study of Schiefele and colleagues (1992), interest was more strongly related to achievement for boys than for girls. Girls were in the study of Ainley and colleagues (2002b) much more persistent even though the task content was evaluated as uninteresting. They reflected the result against other studies, concluding that boys and girls tend to be similar on high interest material or situations, but with low interest material boys perform poorer, which is likely due to reduced effort. It has to be noted, however, that their study was about reading texts of different topics, and girls have constantly had an advantage in reading tasks (Halpern, 2000). Indeed, Thuneberg and colleagues (2014) found that in the science center context, the novelty of the situation produced stronger effects on girls' on learning outcomes indirectly via their situation motivation. Thus, it is likely that also in regard to interest, gender differences are partially topic-specific and in the context of a mathematics exhibition girls who often are less oriented in mathematics at least during their later school career (Eccles, 2011), may benefit more from the situational factors.

\section{Out-of-school education, learning and interest}

Informal education - as it is defined since the 1960s' mainly by the UNESCO report Learning to be (Faure et al., 1972) - means learning taking place outside the formal education system. It was considered until the 1990s very often only as a criticism against the school (Gardner, 1991; Illich 1971). Since the 1990s it has become a widely accepted and integrated part of school systems in many countries especially in regard to science education (Fenichel \& Scheinburger, 2010). Despite this development, there is relatively little theoretical or empirical research on it (Osborne \& Dillon, 2008) and the beliefs about its effectiveness in enhancing learning and not only motivation is mainly based on anecdotal evidence (see Thuneberg et al., 2014).

The terminology of formal education and informal learning has been clearly defined in the literature for decades (e.g. Bitgood, 1988; Coombs, 1968). However, these terms do not completely cover education that happens during school time and according to the curriculum, but uses settings and institutes outside the physical school building. Out-of-school education is a term included in school legislation in several countries, and it refers to using informal education sources for formal education. It forms a pedagogical link between formal education and informal learning (Braund \& Reiss, 2007; Rennie, Feher, Dirking \& Falk, 2003; Salmi, 1993). The context of the present study, science centre education, is one form of out-of-school education.

The methods of informal education have traditionally been used in teaching natural sciences, for example biology, geography or science (e.g. Braund \& Reiss, 2004; Rennie et al., 2003). For mathematics there has only been few activities related to out-of-school education and learning (Fenyvesi, Koskimaa \& Lavicza 2015). There is some evidence from earlier decades that informal sources may have strong effects on learning (Maarschalk, 1986), but especially regarding science center education the studies have mainly concentrated on its effects on motivation (Salmi 1993, 2003; 2010; Tan Wee Hin \& Subramaniam, 2003; Osborne \& Dillon, 2008; 
Fenichel \& Scheingruber, 2010). The results show that science centre education has positive effects on motivation, but very little is known about whether it enhances learning too (cf., Thuneberg et al., 2014), especially in the context of mathematics. There is also little research on how situational interest or motivation, which is often awakened in the science center context (Salmi, 1993), influences learning outcomes, even though this is a perfect context for instructors to "catch" and also "hold" pupils' interest by manipulating the learning environment as suggested by Urdan and Turner (2005). The present study provides a unique opportunity to study the effects of situational factors on learning outcomes as mathematics is a subject which many pupils find unpleasant or uninteresting (Wang, 2012). The 2011 TIMMS study (Mullis, Martin, Foy \& Arora, 2012) shows that nearly half of the fourth grade pupils internationally liked learning mathematics but the proportion of them dropped to $31 \%$ by the eighth grade. Thus, the sixth graders of the present study are at the age when liking of and interest in mathematics in general is declining. Moreover, as pupils proceed further in their school career they begin to do more gendered choices based partly on motivational and social factors (Eccles, 2011), and mathematics has been traditionally been considered as boys' domain (Halpern, 2000) - even if recent research shows that at least at this age, girls outperform boys also in school mathematics (Kenney-Benson, Pomerantz, Ryan \& Patrick, 2006) and more general mathematical thinking skills (Vainikainen, 2014) mainly due to their more positive attitudes.

\section{The present study}

The context of this study was a mobile interactive mathematics exhibition "Discover the Art of Math", to which entire school classes were taken to as a part of their mathematics instruction. The pupils visited it and participated in experimental learning session in order to acquire knowledge and skills that would support the curricular mathematics learning goals of 12-13-year-old sixth graders. The exhibition was based on and inspired by the works of Theo Jansen, a Dutch artist who has created many projects that involve art, math and technology. In 1990, he began what he is known for today: building large animals out of animated works are a fusion of art and engineering - PVC-plastics that are able to "live" on their own. The exhibition consisted of eight interactive, "hands-on" exhibition objects, which the students were allowed to use, test, explore and learn by their own will during 45 minutes time. After that they attended a 45 minutes workshop, in which they were allowed to build their own structures and creatures using small "lego" type of pipes and circles. Pupils learned how to build concrete geometrical models and physical structures based on abstract instructions, for example how to create a $3 \mathrm{D}$ box based on a $2 \mathrm{D}$ square.

The individual work was combined into group work by putting together different items. The exhibition guide was in an introductory and tutorial role. The classroom teacher was just responsible for practical arrangements, not as an active pedagogist. The exhibition was partly funded by NorPlus - education program and it was created by Energiakeskus. It was touring from August 2013 to October 2014 in Innovatum Science Centre, Trollhättan, Sweden; Technical Museum, Stockholm, Sweden; Z(in)OO Science Centre, Cesis, Latvia; and Energiakeskus Science Centre, Tallinn, Estonia. The present study reports only of the Trollhättan and the Latvian exhibition visits as the assessment data for the later visits were not yet available at the time of writing this article.

\section{Research questions and hypotheses}

The aim of the present study is to evaluate, whether individual and situational interest influences the learning outcomes of 12-years-old pupils in a science center mathematics exhibition, and whether the pattern is similar for girls and boys. This is done by fitting a structural equation model on the data of 793 sixth graders from Latvia and Sweden. The research questions and the hypotheses to be tested are:

Q1: Does individual interest in mathematics predict better topic-specific knowledge prior to the science center visit and higher performance in the post-test after the visit when the effect of general cognitive competences is taken into account?

H1: Interest in mathematics predicts positively both pre- and post-test results, but the effect is weak when cognitive competences are controlled for (Ainley, Hidi \& Berndorff, 2002a; Van Yperen, 2003). 
Q2: Does individual interest predict situational interest? Does situational interest predict topic-specific knowledge after the science center visit beyond individual interest?

H2: Higher individual interest predicts situational interest (Renninger \& Hidi, 2011). Situational interest has an additional effect on post-test performance as science center visit may be a positive experience also for pupils who are in general not very interested in mathematics (Ainley et al., 2002a; Durik \& Harackiewicz, 2007).

Q3: Are the learning outcomes and the effects of individual and situational interest on them similar for girls and boys?

H3: Boys have a slight advantage in the pre-test but girls close both gaps in the post-exhibition assessment (Thuneberg et al., 2014). Boys experience stronger situational interest (Ainley et al., 2002b), but situational factors may have a stronger influence on learning for girls (Thuneberg et al., 2014).

\section{Methodology}

The data were drawn from a study, in which sixth and seventh grade school classes were taken into a mathematics exhibition which toured in three countries. The present study reports of the first two data collections that were done in Sweden in the autumn 2013 and in Latvia in the spring 2014. Afterwards, the exhibition continued to Estonia and back to Sweden, but those data were not yet available for the present study.

\section{Participants}

The participants were 793 sixth or seventh graders from Latvian $(\mathrm{N}=408)$ and Swedish $(\mathrm{N}=385)$ schools. The participating classes were randomly selected from all school classes that expressed their interest in visiting the exhibition. 384 of the pupils were girls and 397 boys (the information was missing from 12 pupils). The mean age of the pupils at the time of the pre-test was $M=12.39, S d=.99$.

\section{Measures}

Two weeks before the science exhibition visit, the pupils completed a pre-knowledge test and a test measuring general cognitive competences, and a questionnaire regarding their attitudes towards learning mathematics in school. Seven to eleven days after the exhibition, they completed a post-test and questionnaire regarding their experiences about learning mathematics in the exhibition.

General cognitive competences. Pupils' general cognitive competences were measured by Raven Standard Progressive Matrices, which addresses the capacity to learn and the capacity to embrace and remember the knowledge once learned in the context of visuo-spatial reasoning (Raven, Raven, \& Court, 2000; 2003). In each item, pupils were asked to identify the missing element, which completes a pattern. The test consisted of five sets of twelve items, which were to be completed within a predefined time limit. The items were coded dichotomously as correct or incorrect (including the items not reached). The final test score was calculated as a sum of correctly solved items within the time limit. The reliability of the test was good ( $\alpha=.89)$.

Pre-and post-tests for topic-specific mathematical knowledge. Pupils' prior topic-specific knowledge and learning outcomes were measured by a test designed for the present study. Originally developed through a pilot study in Finland, the test consisted of 26 items measuring pupils' understanding of mathematical phenomena, which were covered by the science center mathematics exhibition (e.g. understanding Pythagoras law, pyramidal structures, symmetric plates, strings, and rotating bodies). Pupils were presented short verbal stimuli followed by one to four statements, and the pupils' task was to judge whether the statements were correct or incorrect. They also had the option to say that they do not know the answer, but for the present study those answers were coded as incorrect. All the items were coded dichotomously. Preliminary analyses using Item Response Theory revealed that two very difficult items had a poor discrimination value, so they were omitted from the further analyses. The final test scores for pre- and post-test were calculated by summarizing the remaining 24 items together. The reliability for the pre-test score was $\alpha=.74$ and for the post-test $\alpha=.81$. 
Individual and situational interest. The Semantic Differential method (Osgood, 1964) was used for measuring pupils' attitudes towards learning mathematics in school settings (pre-test) and in the mathematics exhibition (post-test). The method has been widely used for measuring children's experiences of different learning contexts especially when the results of informal learning and formal education have been compared (Salmi 2012). The 14-item scale consisted of three factors, of which only the interest factor was used in the present study. The pupils had to evaluate three pairs of adjectives on a five-point scale (e.g. Learning mathematics in school is/in the science center was interesting... boring). The reliability of the interest scale was $\alpha=.64$ for the pre-test and $\alpha=.73$ for the post-test.

\section{Data Analyses}

Descriptive statistics were calculated with SPSS22 and item parameters for the preliminary analyses in Mplus. Gender differences in performance were initially studied by repeated measures ANOVA in SPSS22. The hypotheses about the effects of interest on learning outcomes were tested by structural equation modelling (SEM) in AMOS22 as this method allows the simultaneous testing of all the relations, taking into account the effects of other variables in the model (see Kline, 2005). The third hypothesis about gender differences was tested by multiple-group SEM, which additionally allows the testing of group differences in both the level of variables and the relations of them. A prerequisite for both multiple-group and repeated measures analyses is measurement invariance of the latent factors. Therefore, measurement invariance of the interest scales across time points and gender groups was checked by constraining first the factor loadings, then intercepts equal, and comparing the change of fit indices to the baseline model (Byrne \& Stewart, 2006). Since the deviation from normality of all variables was within the recommended limits (Kline, 2005), maximum likelihood estimation was used in all the analyses. The models were considered having a good fit with CFI and TLI > .95, and RMSEA $<.06 . \chi^{2}$-values are also reported but due to the sample size significant $p$-values were to be expected.

\section{Results}

First, descriptive statistics were calculated for the whole data and for girls and boys separately. The means and the standard deviations are presented by gender in Table 1.

Table 1

Descriptive statistics of the variables used in the modeling for girls and boys

\section{Measure}

$\underline{\text { Pre-test }}$

Raven progressive matrices

Mathematical knowledge

Individual interest in mathematics - item 1

Individual interest in mathematics - item 2

Individual interest in mathematics - item 3

Post-test

Mathematical knowledge

Situational interest in exhibition - item 1

Situational interest in exhibition - item 2

Situational interest in exhibition - item 3

\begin{tabular}{l|l|l|l|l|}
$\mathbf{N}$ & Min & Max & Mean & Sd \\
$353 \mid 362$ & $0 \mid 8$ & $51 \mid 54$ & $34.28 \mid 33.71$ & $8.31 \mid 7.56$ \\
$360 \mid 355$ & 0 & $20 \mid 21$ & $9.54 \mid 9.75$ & $4.61 \mid 4.48$ \\
$346 \mid 346$ & 1 & 5 & $3.60 \mid 3.60$ & $1.15 \mid 1.28$ \\
$343 \mid 344$ & 1 & 5 & $4.23 \mid 4.22$ & $1.06 \mid 1.07$ \\
$337 \mid 337$ & 1 & 5 & $3.66 \mid 3.55$ & $1.00 \mid 1.13$ \\
$334 \mid 348$ & 0 & 22 & $10.99 \mid 11.39$ & $4.81 \mid 4.99$ \\
$320 \mid 336$ & 1 & 5 & $3.90 \mid 3.97$ & $1.11 \mid 1.13$ \\
$315 \mid 334$ & 1 & 5 & $3.77 \mid 3.79$ & $1.03 \mid 1.06$ \\
$298 \mid 327$ & 1 & 5 & $3.93 \mid 3.89$ & $1.04 \mid 0.98$ \\
\hline
\end{tabular}

The values for girls and boys are separated by a vertical bar $\mathrm{N}=$ Number of respondents, $\mathrm{Min}=$ Minimum value, $\mathrm{Max}=$ Maximum value, $\mathrm{Sd}=\mathrm{Standard}$ deviation

Before testing how interest influences learning, the development of girls' and boys' performance in the knowledge test was analyzed without covariates by using repeated measures ANOVA. The results are presented in Figure 1. The improvement of performance in the test was statistically significant (Wilks' Lambda $=.868$, 
$\mathrm{F}=94.546, \mathrm{df}=1, \mathrm{p}<.001)$ but the small gender difference in favor of boys in the post-test $(\mathrm{t}=-1.057, \mathrm{p}=.291)$ or the interaction were not (Wilks' Lambda $=.996, \mathrm{~F}=2.603, \mathrm{df}=1, \mathrm{p}=.107$ ). Thus, both girls and boys knew more about the topics of the exhibition after the visit compared to the situation prior to the science center visit and contrary to our third research hypothesis - there were no gender differences in the level of knowledge.

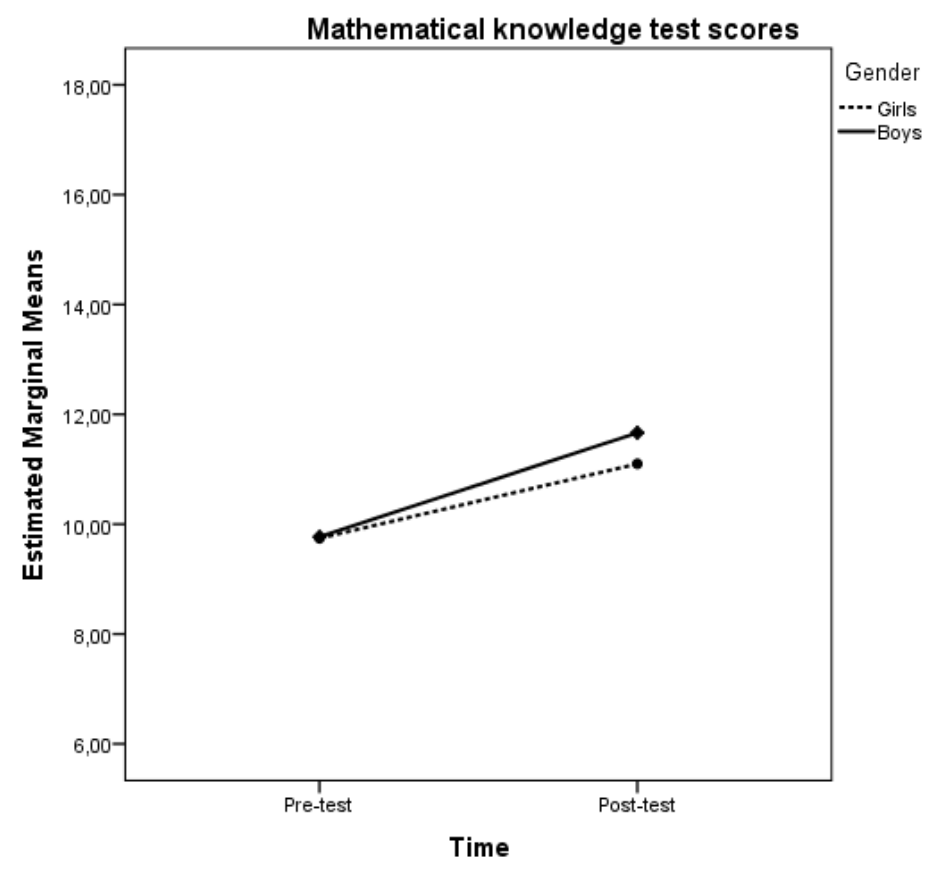

Figure 1. Girls' and boys' performance in the pre-and post-test for topic-specific knowledge covered by the mathematics exhibition. The improvement of knowledge is statistically significant but the small gender difference or the interaction are not.

Next, measurement invariance of the interest scale across the two situations (school mathematics in general and mathematics in the exhibition context) and the two gender groups was tested in two stages. In the first stage the analyses were performed using the whole data. First the factor loadings and then the intercepts across the pre- and the post-tests were constrained equal. The changes in the fit indices are presented in Table 2. The table shows that constraining factor loadings influenced the indices only minimally but constraining all the intercepts caused the fit indices to drop. Therefore the intercept of the second item was released. This is an acceptable procedure when the focus of the study is not in latent mean comparison but in studying the relations of the variables (Steenkamp \& Baumgartner, 1998). At the second stage the data was divided by gender, and measurement invariance was tested simultaneously across time and gender (see Table 2). The scale was measurement invariant across gender groups but the intercept of the second item had to be released because of the problems in the first stage of testing. The table also shows that constraining the latent means equal across gender groups did not influence the indices but doing it across the time points did. Thus, contrary to our third research hypothesis there were no statistically significant gender differences in interest either but the pupils reported somewhat higher levels of situational interest than interest in school mathematics. 
Table 2

Measurement invariance and statistical significance of the latent mean differences of the interest scales

\begin{tabular}{|c|c|c|c|c|c|c|}
\hline Model & $\chi^{2}$ & $d f$ & CFI & TLI & RMSEA & $p$ \\
\hline \multicolumn{7}{|l|}{ Across pre- and post-tests } \\
\hline Baseline model & 20.217 & 8 & .987 & .965 & .044 & .010 \\
\hline Factor loadings constrained equal & 27.234 & 10 & .981 & .960 & .047 & .002 \\
\hline Measurement intercepts constrained equal except for item 2 & 27.236 & 11 & .982 & .966 & .043 & .004 \\
\hline Latent means constrained equal & 69.840 & 15 & .936 & .888 & .078 & $<.001$ \\
\hline \multicolumn{7}{|l|}{ Across gender groups and pre- and post tests } \\
\hline Baseline model & 22.601 & 16 & .992 & .980 & .023 & .125 \\
\hline Factor loadings constrained equal & 33.367 & 22 & .987 & .975 & .026 & .057 \\
\hline Measurement intercepts constrained equal except for item 2 & 36.720 & 25 & .987 & .978 & .025 & .061 \\
\hline Latent means constrained equal across gender & 37.623 & 27 & .987 & .979 & .022 & .084 \\
\hline All latent means constrained equal & 79.922 & 28 & .941 & .911 & .049 & $<.001$ \\
\hline
\end{tabular}

$\mathrm{CFI}=$ Comparative fit index, TLI=Tucker-Lewis index, RMSEA=Root mean square error of approximation

When the factors were concluded sufficiently measurement invariant, a structural equation model was built for testing the relations of the variables. Individual interest and prior knowledge of the contents of the mathematics exhibition were used in predicting situational interest and mathematical knowledge test results after the exhibition, controlling for the effects of general cognitive competences (the Raven test). Raven turned out to be unrelated to situational interest, so the path was removed from the model. Similarly, the pre-test for mathematical knowledge did not predict situational interest and the path was removed. Moreover, contrary to the first research hypothesis, individual interest was unrelated to prior mathematical knowledge. As there was no gender difference in the latent means in the invariance testing, they were constrained equal across gender groups. Accordingly, constraining the means of all the manifest cognitive variables equal across gender groups even slightly improved the fit indices, so - as already shown by repeated measures ANOVA - there were no gender differences in any of the cognitive measures either. Finally, all the paths were constrained equal across gender groups and again the fit indices even improved. The final trimmed and constrained model (CFI $=.977$, $\mathrm{TLI}=.969, \mathrm{RMSEA}=.024, \chi^{2}=96.000, \mathrm{df}=67, \mathrm{p}=.012$ ) is presented in Figure 2 . The path coefficients for girls and boys are separated with a vertical bar, but none of the small differences was statistically significant. 


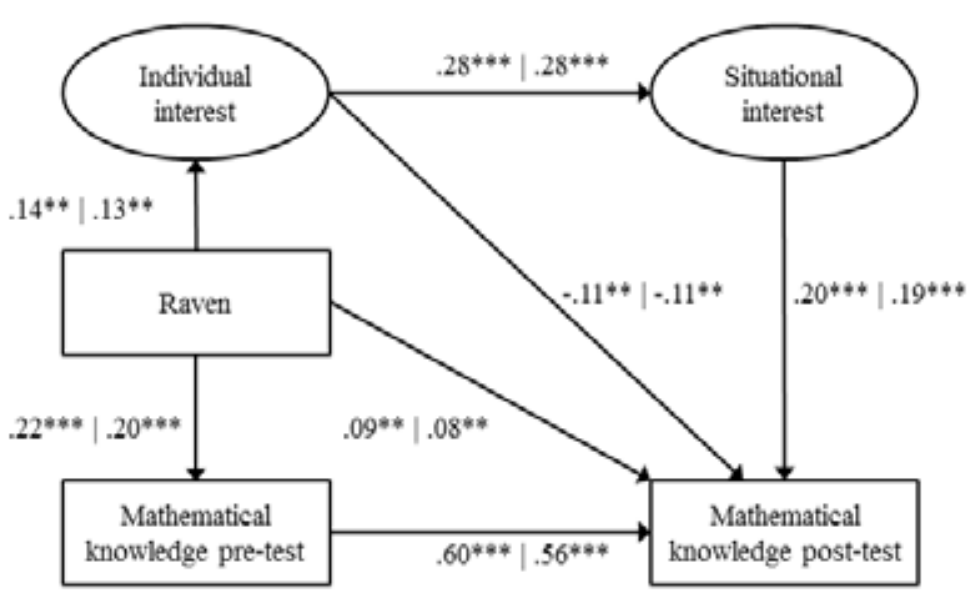

Figure 2. The final structural equation model used in the study. The individual factor indicators and disturbances are not displayed. Factor loadings and intercepts except one are constrained equal across time points and gender groups. All means and paths are constrained equal across gender groups. The path coefficients of girls and boys, respectively, are separated with a vertical bar. ${ }^{* *} \mathrm{p}<.001,{ }^{* *} \mathrm{p} .<01$. The model explained $43 \%$ of the variance of the post-test for girls and $38 \%$ for the boys.

The figure shows that the absolutely strongest predictor of the post-test for mathematic knowledge was prior knowledge of the contents of the exhibition. Prior mathematical knowledge, in turn, was as expected positively predicted by general cognitive competences as measured by the Raven test. In addition, the Raven test scores predicted weakly but statistically significantly the mathematical post-test scores, which means that pupils with higher general cognitive competences learned slightly more in the exhibition.

The Raven test predicted also weakly but statistically significantly the pupils' individual interest in school mathematics, so pupils with higher cognitive competences were more interested in mathematics. Individual interest was a moderate predictor of situational interest, which in turn had a moderate positive effect on the mathematical post-test scores. Thus, the second research hypothesis was supported. Individual interest, however, predicted the post-test scores negatively albeit very weakly $(\beta=-.110, p=.033)$. As this was contrary to all the expectations, including the first research hypothesis, this needed further analyses to confirm the interpretation. Therefore, it was tested whether this unexpected effect could be due to so called suppression, which means that another variable in a model extracts the relevant variance of the variable in question, producing a controversial side effect (see Cheung \& Lau, 2008). Indeed, without other variables in the model there was absolutely no connection between the individual interest factor and the post-test performance $(\beta=-.018, p=.712)$, so only the part of the variance which was not related to the situational interest factor explained the slightly negative coefficient. As the model anyways fit the data better with this path than without it, it was kept in the model, but the suppression needs to be taken into account when interpreting the results.

\section{Discussion}

The aim of the present study was to evaluate, whether individual and situational interest influences the learning outcomes of 12-years-old pupils in an out-of-school learning context. Almost 800 12-years-old pupils were taken into a science centre mathematics exhibition in Latvia and Sweden, measuring their prior knowledge of the contents of the exhibition, general cognitive competences and individual interest in school mathematics before the visit, and their situational interest and learning outcomes after the exhibition. In addition to studying the learning outcomes and the role of interest in them in general, special attention was paid to possible gender differences in them. As initial analyses showed that the pupils really learned during the exhibition - that is, they got higher scores in the knowledge test measuring the content areas of the exhibition after the visit compared to 
their performance prior to the visit (cf., Salmi, Thuneberg \& Vainikainen, submitted; Thuneberg et al., 2014) we proceeded to testing our research hypotheses regarding the role of interest and the gender differences in it.

In the first hypothesis we expected that individual interest in school mathematics would predict both pre- and post-test results positively. In other words, we assumed that pupils who are more interested in mathematics would know more of the exhibition topics already beforehand and that they would also learn more during the exhibition. The analyses proved both assumptions incorrect: Individual interested turned out to be uncorrelated with knowledge test scores both before and after the exhibition, and in structural equation modelling there was even a slightly negative relation between individual interest and performance after the exhibition caused by so called suppression (Cheung \& Lau, 2008). This means that some other variable in the model, in this case situational interest, extracted the relevant variance of individual interest, producing a controversial direct side effect. Regardless of this, it can be concluded that individual interest was unrelated with both pre- and post-test scores. This was contrary to our expectations, even though we did not expect the effects to be strong due to the young age of the participants (cf., Vainikainen, 2014) and the fact that we had controlled for both prior content-specific knowledge (cf., Ainley et al., 2002a; Schiefele et al., 1992; Van Yperen, 2003) and the pupils' general cognitive competences (cf., Vainikainen, 2014). The results showed, however, that general cognitive competences predicted both better pre-test performance and higher individual interest, and that pupils with higher cognitive competences also learned slightly more during the exhibition. This corresponds the earlier results of Thuneberg and colleagues (2014), showing that a science center exhibition produces stronger effects on the learning outcomes for pupils on above the average performance level. Like in their study, also here the strongest predictor of performance for both boys and girls was prior topic-specific knowledge.

In the second hypothesis we assumed that higher individual interest would predict situational interest and that situational interest would have an additional effect on post-test performance. The results proved both assumptions correct: Just as in the studies reviewed by Renninger and Hidi (2011), which were, however, not about out-of-school learning specifically, pupils with higher individual interest in school mathematics also developed stronger situational interest in the mathematics exhibition. Situational interest in the present study predicted higher performance in the post-test of topic-specific knowledge even when prior knowledge and general cognitive competences were taken into account. On the one hand, these results fit together with Renninger's (2007) assumptions about the mechanisms of interest and learning in informal settings: it is possible that also with the 12-years-olds of the present study, a more developed interest is related to more task-specific goals and better self-regulation capacity, which influences their participation in the situation and is visible in their learning outcomes. On the other hand, individual interest did not predict learning and there were clearly other factors besides it that explained the variance of situational interest, so it seems that a less developed interest can also be beneficial (cf., Ainley et al., 2002; Durik \& Harackiewicz, 2007) in out-of-school learning contexts. In this, the results are somewhat controversial with how Renninger (2007) describes the role of developed interest and motivation almost as prerequisites for active participation instead of "aimless" experience seeking in informal learning settings. But this is maybe due to the small but important distinction between informal education and out-of-school education: The mathematics exhibition as an out-of-school learning situation had nevertheless a clear structure and predefined learning goals, and the pupils also received some formal-like instruction during the visit. Therefore, based on the results of the present study compared to the earlier research, more research is clearly needed in how the mechanisms of situational interest and motivation work in the science center context specifically.

In our third hypothesis we expected to find gender differences in both learning outcomes and situational interest. As boys have traditionally been more oriented towards mathematics (Eccles, 2011) and more interested in it (Frenzel et al., 2007: 2010), we expected them to know more about the contents of the mathematics exhibition before the visit. However, as the novelty aspect of a science center visit has in previous studies produced stronger learning effect for girls (Salmi et al., submitted, Thuneberg et al., 2014), we did not expect to find any gender differences in the post-test situation - regardless of the evidence showing that boys may experience stronger situational interest (Ainley et al., 2002b). 
The results showed that there were no gender differences in either learning outcomes or interest. That is, girls and boys had equal prior knowledge about the contents of the mathematics exhibition before the visit and they also learned equally much during the exhibition. Similarly, both girls and boys experienced somewhat stronger situational interest in the exhibition compared to individual interest in school mathematics, and there were no statistically significant gender differences in the relations between the variables either. The results were controversial with the earlier results obtained the science center context (Salmi et al., submitted, Thuneberg et al., 2014) in that girls did not have any gap to close when they came to the science center. This may be due to the relatively unusual topic of the exhibition (cf., Fenyvesi et al., 2015), so called 4D-mathematics, which was based on art and handicrafts by Theo Jansen. After all, girls have during the last decade begun to perform better than boys also on the traditional male-dominated school subjects like mathematics (Kenney-Benson et al., 2006). Besides the learning outcomes, the results were controversial with earlier research also regarding the strength and the role of interest in explaining learning. Boys' interest was not related to performance stronger than it was for girls (cf., Schiefele et al., 1992) but on the other hand, the science center learning situation itself was generally interesting, which has been shown to reduce performance differences between girls and boys (Ainley et al., 2002b). However, unlike in the study of Thuneberg and colleagues (2014), we did not find the novelty effect being different for the two genders either. It has to be noted, however, that our measure addressed the novelty of situation only indirectly within the situational interest measure, whereas in the other study it was much more straightforwardly defined as visiting a science exhibition for the first time ever.

Our study had other limitations as well. Even though exactly the same exhibition toured in the two countries, there may be differences in the practical organization of it which could not be addressed in this study. Therefore, further research is needed regarding the implementation effects. Also, the fact that individual interest was hardly at all related with performance can be partially due the limited measures of interest used in the present study. We used a three-item factor from a semantic differential scale for measuring the pupils' experiences of learning mathematics in general and in the science center exhibition context, but other approaches might have been more accurate here. But as Renninger and Hidi (2011) state in their comprehensive review, "Constructing such measures [for differentiating between the stages of interest] is difficult because of the changing and individual nature of the relation among affect, value, and knowledge that is the presumed basis of movement between phases of interest." Also, measurement of the psychological state of interest should preferably be done during the learning process (Ainley et al., 2002a), not before or after it as was done here. However, as often in larger-scale studies, real-time data collection was in the present study not possible due to practical reasons.

\section{Interest and motivation}

The present study has concentrated on interest and its role in learning in the science centre settings, but there is a significant overlap between interest and motivation (Durik \& Harackiewicz, 2007). Therefore, the results of the present study can be reflected against what is known about motivation and informal learning. In the science center learning context it has been claimed that interest could be the link bridging situation and intrinsic motivation (Salmi, 2003) and the results of the present study support this idea even though motivation was not directly assessed. Interest-based, self-determined forms of learning motivation provide the most favorable learning outcomes, and on the other hand organization of the learning environment can spark interest before personal motivation develops (Fenichel \& Schweingruber, 2010; Renninger \& Hidi, 2011). Thus, out-of-school learning - formal-like teaching in an informal context - can provide an excellent opportunity for enhancing pupils' interest and motivation towards learning science and mathematics.

Novelty is the key factor to create the interest and situation motivation in the science centers. The shock of a new setting can be addressed by the so called "sniff around corners" method (Balling \& Falk, 1981). It works also as a "head-start" for the learning process, and the self-determination theory (SDT; see Reeve, Ryan, Deci \& Jang, 2008) underlines the fact that the students must perceive fulfillment of their psychological needs, autonomy, competence, relatedness, during instruction. It has also a clear link to intrinsic learning motivation. 
The content of the exhibition is essential: the meaningful experiences are closely connected with a positive development of interest in the subject. Of course, the starting point of this process of growing interest lies within the person, but the content and interaction define the development of situational and individual interests (Hidi \& Renninger, 2006). The conflict between earlier knowledge and capacities and the goals that can be reached by own learning activities start this process (Salmi 1993; 2003). The classroom discourse intervention on teachers' practice and students' motivation to learn mathematics and science has given recently very encouraging results (Kiemer, Groschner, Pehmer, \& Seidel, 2015). However, informal learning settings might be interest-based and thus motivate also the students who otherwise are not very academically oriented.

\section{Conclusions}

There has been a lot of anecdotal evidence related to learning mathematics via informal education and science center exhibitions. However, there has been a clear lack of studies measuring the actual learning outcomes of children visiting mathematics exhibitions. This study gives some of the very first, encouraging results of that teaching mathematics in a science center setting can be fruitful both in regard to learning outcomes but also as a trigger of interest in mathematical phenomena. The standard methods and measurements presented in this study offer common ground for comparative international results. This study also supports earlier findings about interest-enhancing strategies, of which "doing a repetitive task in many different ways" is central in an out-of-school learning context (see Reeve et al., 2008). An open learning environment - a science center exhibition - gives all kinds of pupils an opportunity to utilize functioning strategies and help them to self-regulate (enhance) their interest, engagement, perseverance, and emotional well-being.

This mathematics exhibition gave the students an opportunity to apply hands-on activities utilizing also arts and handicrafts. This clearly predicted higher interest and learning both for girls and for boys. To take the next step beyond the findings of the present study, more attention should be paid to how this kind of situational interest and motivation can be utilized in enhancing learning outcomes of children of other age groups in other learning environments. More research is also needed from science center contexts about exhibitions of different mathematical contents. The present study took the first important step in this direction, opening a new path for studying the mechanisms of interest and learning in out-of-school settings.

\section{References}

Ainley, M., Hidi, S., \& Berndorff, D. (2002a). Interest, learning, and the psychological processes that mediate their relationship. Journal of Educational Psychology, 94(3), 545-561. doi:10.1037//0022-0663.94.3.545

Ainley, M., Hillman, K., \& Hidi, S. (2002b). Gender and interest processes in response to literary texts: Situational and individual interest. Learning and Instruction, 12, 411-428.

Artigue, M. \& Blomhøj, M. (2013). Conceptualising inquiry based education in mathematics. ZDM - The International Journal on Mathematics Education, 45(6), 901-909.

Balling \& Falk, J. (1981). A perspective on field trips: Environmental effects on learning. Curator 23/4, 229-240

Bitgood, S. (1988). A comparison of formal and informal learning. Technical Report No. 88-10. Jacksonville, AL: Center for Social Design.

Braund, M. \& Reiss, M. (2004). Learning science outside the classroom. London: Routledge.

Braund, M. \& Reiss, M. (2007). What does out-of-school learning offer school science? The Science Education Review, 6, 35-37

Byrne, B.M. \& Stewart, S.M. (2006). The MACS approach to testing for multigroup invariance of a second-order structure: A walk through the process. Structural Equation Modeling: A Multidisciplinary Journal, 13(2), 287-321. doi:10.1207/s15328007sem1302_7 
Cheung, G. W. \& Lau, R. S. (2008). Testing mediation and suppression effects of latent variables. Bootsrapping with structural equation models. Organisational Research Methods, 11(2), 296-325. doi: $10.1177 / 1094428107300343$

Coombs, P. (1985). The world crisis in education. The view from the eighties. Oxford: Oxford University Press.

Csikszentmihalyi, M. \& Hermanson, K. (1995). Intrinsic motivation in museums: why does one want to learn more? In Falk, J. \& Dierking, L. (Eds.) Public Institutions for Personal Learning, pp.67-79. American Association for Museums: Washington DC.

Durik, A., \& Harackiewicz, J. M. (2007). Different strokes for different folks: How individual interest moderates the effects of situational factors on task interest. Journal of Educational Psychology, 99, 597-610.

Eccles, J. (2011). Gendered educational and occupational choices: Applying the Eccles et al. model of achievement-related choices. International Journal of Behavioural Development, 35(3), 195-201.

Faure, E., Herrera, F., Kaddoura, A-R., Lopes, H., Petrovsky, A.V., Rahnema, M., \& Champion Ward, F. (1972). Learning to be: The world of education today and tomorrow. Paris: UNESCO.

Fenichel, M. \& Schweingruber, H. (2010). Surrounded by science: Learning science in informal environments. Board of Science education, Center of education, Division of behavioral and social sciences and education. Washington, DC: The National Academic Press.

Fenyvesi, K., Koskimaa, R. \& Lavicza, Z. (2015). Experiential education of mathematics: Art and games for digital natives. Kasvatus \& Aika 1/2015.

Frantz-Pittner A., Grabner S., \& Bachmann G. (2011). Science Center Didaktik. Hohengehren: Schneider Verlag.

Frenzel, A., Goetz, T., Pekrun, R., \& Watt, H. (2010). Development of Mathematics Interest in Adolescence: Influences of Gender, Family, and School Context. Journal of Research on Adolescence, 20 (2), 507-537.

Frenzel, A. C., Pekrun, R., \& Goetz, T. (2007). Girls and mathematics-a "hopeless" issue? A control-value approach to gender differences in emotions towards mathematics. European Journal of Psychology of Education, 22, 497-514.

Gardner, H. (1991). The unschooled mind. How children think and how schools should teach. New York: Basic Books.

Gomez-Chacon, I. M. (2000). Affective influences in the knowledge of mathematics. Educational Studies in Mathematics, 43 (2), 149-168.

Halpern, D. F. (2000). Sex Differences in Cognitive Abilities. Third Edition. Mahwah, NJ: Lawrence Erlbaum Associates.

Hannula, M. (2012). Exploring new dimensions of mathematics-related affect: embodied and social theories. Research in Mathematics Education, 14 (2), 137-161.

Hidi, S. \& Ainley, M. (2009) Interest and self-regulation: Relationship between two variables that influence learning. In D. Schunk \& B. Zimmerman, (Eds.) Motivation and self-regulated learning. Theory, research and applications. New York/London: Routledge, Taylor \& Francis group.

Hidi, S., \& Harackiewicz, J. (2000). Motivating the academically unmotivated: A critical issue for the 21 st century. Review of Educational Research, 70, 151-179.

Hidi, S., \& Renninger, K.A. (2006). The four-phase model of interest development. Educational Psychologist, 41(2), 111-127.

Illich, I. (1971). Deschooling society. New York: Harper and Row.

Kenney-Benson, G.A., Pomerantz, E.M., Ryan, A.M., \& Patrick, H. (2006). Sex differences in math performance: The role of children's approach to schoolwork. Developmental Psychology, 42(1), 11-26. doi:10.1037/00121649.42.1.11 
Kiemer, K., Groschner, A., Pehmer, A.-K., Seidel, T. (2015). Effects of a classroom discourse intervention on teachers' practice and students' motivation to learn mathematics and science. Learning and instruction 35, 94-103.

Kline, R.B. (2005). Principles and Practice of Structural Equation Modeling. 2nd edition. New York: The Guildford Press.

Ma, X. \& Kishor, N. (1997). Assessing the relationship between attitude toward mathematics and achievement in mathematics: A meta-analysis. Journal for Research in Mathematics Education, 28 (1), 26-47.

Maarschalk, J. (1986). Scientific literacy through informal science teaching. European Journal of Science Education, 8(4), 353-360.

Mullis, I.V.S., Martin, M.O., Foy, P., \& Arora, A. (2012). TIMMS 2011 International Results in Mathematics. Amsterdam: International Association for the Evaluation of Educational Achievement.

Osborne, J.F., \& Dillon, J. (2008). Science education in Europe. London: Nuffield Foundation.

Osgood, C. E. (1964). Semantic differential technique in the comparative study of cultures. American Anthropologist, 66 (3), 171-200

Raven, J., Raven, J.C., \& Court, J. (2000). Section 3. Standard Progressive Matrices, 2000 Edition. Oxford: Elsfield Hall.

Raven, J., Raven, J.C., \& Court, J. (2003). Manual for Raven's progressive matrices and vocabulary scales. Oxford: OPP Limited.

Reeve, J., Ryan, R., Deci, E. \& Jang, H. (2008). Understanding and promoting autonomous self-regulation: a self-determination theory perspective. In D. Schunk \& B. Zimmerman (Eds.), Theory, research and applications. New York/ London:Taylor \& Francis group.

Rennie, L., Feher, E., Dirking, L. \& Falk, J. (2003). Towards an agenda for advancing research on science learning in out-of-school settings. Journal of Research in Science Teaching, 40(2), 112-120.

Renninger, A.K. (2007). Interest and motivation in informal science learning. Retrieved 5.3.2015 from http://w. informalscience.org/images/research/Renninger_Commissioned_Paper.pdf.

Renninger, K.A., \& Hidi, S. (2011). Revisiting the conceptualization, measurement, and generation of interest. Educational Psychologist, 46(3), 168-184. doi:10.1080/00461520.2011.587723

Renninger, K. A., Sansone, C., \& Smith, J. L. (2004). Love of learning. In C. Peterson

\& M. E. P. Seligman (Eds.) Character strengths and virtues: A handbook and

classification, pp. 161-179. New York: Oxford University Press.

Resnick, L.B. (1987). The 1987 presidential address: Learning in school and out. Educational Researcher, 16(9), 13-54.

Salmi, H. (1993). Science Centre Education. Motivation and Learning in Informal Education. Department of Teacher Education, University of Helsinki, Research Report 119.

Salmi, H. (2003). Science centres as learning laboratories. International Journal of Technology Management 25 (5), 460-476.

Salmi, H. 2010. Science centre pedagogics and academic teacher education [In Finnish]. In A. Kallioniemi, A. Toom, M. Ubani, and H. Linnansaari, H. (Eds.). Academic class teacher education: 30 years of theory, practice, and Master's degrees [In Finnish]. Kasvatusalan tutkimuksia 52: 377-406. Helsinki: Finnish Society for Educational Research.

Salmi, H. (2012). Evidence of bridging the gap between formal education and informal learning. Reflecting Education 8 (2), 45-61. 
Salmi, H., Sotiriou, S. \& Bogner, F.( 2009). Visualising the invisible in science centres and science museums: Augmented Reality (AR) technology application and science teaching. In Karacapilidis, N. (Ed.) Web-Based Learning Solutions for Communities of Practice: Virtual Environment for Social and Pedagogical Advancement,pp. 185-208. New York: Information Science Reference.

Salmi, H., Thuneberg, H. \& Vainikainen, M.-P. (revision submitted). How do engineering attitudes vary by gender and motivation? Attractiveness of outreach science exhibitions in four countries. European Journal of Engineering Education.

Schiefele, U., Krapp, A., \& Winteler, A. (1992). Interest as a predictor of academic achievement: a recta-analysis of research. In K. Renninger, S. Hidi \& A.Krapp (Eds.) The role of interest learning and development, pp. 183-212. Hillsdale, NJ: Erlbaum.

Steenkamp, J.-B.E.M., \& Baumgartner, H. (1998). Assessing measurement invariance in cross-national consumer research. Journal of Consumer Research, 25(1), 78-107.

Tan Wee Hin, L. \& Subramaniam, R., (2003). Science and technology centres as agents for promoting science culture in developing nations. International Journal of Technology Management, 25(5), 413-426.

Thuneberg, H., Salmi, H., \& Vainikainen, M.-P. (2014). Tiedenäyttely, motivaatio ja oppiminen [Science exhibition, motivation and learning]. Psykologia, 49 (6), 420-435.

Urdan, T. \& Turner, J. (2005). Competence motivation in the classroom. In A. Elliot \& C.Dweck (Eds.) Handbook of Competence and Motivation. The Guildford press, New York.

Vainikainen, M.-P. (2014). Finnish primary school pupils' performance in learning to learn assessments: A longitudinal perspective on educational equity. University of Helsinki, Department of Teacher Education Research Report 360. Helsinki: Unigrafia.

Van Yperen, N. (2003). Task interest and actual performance: The moderating effects of assigned and adopted purpose goals. Journal of Personality and Social Psychology, 85(6), 1006-1015. doi:10.1037/00223514.85.6.1006

Wang, M.-T. (2012). Educational and career interests in math: A longitudinal examination of the links between classroom environment, motivational beliefs, and interests. Developmental Psychology, 48(6), 1643-1657. 